\title{
Crystallization Optimizing of Cefradine
}

\author{
Lei $\mathrm{Du}^{*}{ }^{* 1}$ and Wenbo Luo ${ }^{2}$ \\ ${ }^{1}$ Application Technology Institute of China Petroleum Engineering Southwest Company, China \\ ${ }^{2}$ College of Light Industry and Food Science of South China University of Technology, China
}

\begin{abstract}
Cefradine crystallization was studied under different conditions. The optimal conditions for crystallization were: dissolving temperature, $15^{\circ} \mathrm{C}$; initial temperature in crystallization, $30^{\circ} \mathrm{C}$; cooling temperature in crystallization, $0^{\circ} \mathrm{C}$; and adding 1,2-propanediol as adjuvant agent with a volume ratio 0.2 of water solution. The yield of cefradine crystallization is about $92 \%$ under these conditions. The purity of cefradine crystals is over $98 \%$ under the same conditions. The average size of cefradine crystal is $500 \mu \mathrm{m}$. The content of cefalexin in crystal is reduced to only $0.36 \%$.
\end{abstract}

Keywords: Cefradine, crystal, crystal seed, optimization.

\section{INTRODUCTION}

Cefradine (cephradine, cephalosporin IV, sefril), 7-[a-D(cyclohexa-1,4-dienyl)- glycyl-amino]-3-methyl-3-cephem4-carboxylic acid $\left(\mathrm{C}_{16} \mathrm{H}_{19} \mathrm{~N}_{3} \mathrm{O}_{4} \mathrm{~S}\right)$, is a first-generation cephalosporin, originally isolated in 1948 [1]. It exhibits broad-spectrum antibacterial activity against gram-positive and gram-negative microorganisms by inhibiting bacterial cell wall synthesis. Cefradine is useful for treatment of infections of the urinary and respiratory tracts, skin, and soft tissues. However, the solubility of cefradine in most solvents is low, resulting in limited bioavailability and/or erratic absorption [2]. The crystallization mainly includes precipitate crystallization, dilution crystallization and reaction crystallization. The crystallization of cefradine belongs to the reaction crystallization which is usually hard to control because of its high reaction rate [3-15]. Therefore, the aim of this study was to optimize the crystallization process to increase the yield and purity of cefradine crystals.

\section{EXPERIMENTAL}

\subsection{Materials}

Commercial crude cefradine was purchased from BETA Inc. (NCPC, China). Standard cefradine and cefalexin were obtained from Sigma. All the other chemicals were of analytical reagent grade; the solutions were prepared with double-distilled water.

\subsection{Preparation of Cefradine Solution and Crystal Seed}

Five (5.00) $\mathrm{g}$ of cefradine was added in $0.25 \% \mathrm{NaHSO}_{3}$ (W/V) solution and dissolved completely by slowly adding 12 $\mathrm{M} \mathrm{HCl}$ while stirring. The solution $\mathrm{pH}$ value was then adjusted to $2.8-2.9$ by adding dimethylamine/ethylenediamine $(1: 2$, $\mathrm{V} / \mathrm{V})$. Next, $5 \%$ of the solution volume was removed and the remained was reserved; we continued stirring this solution at $25^{\circ} \mathrm{C}$ and used it to seed nucleation after ultrasonic wave radiation $\left(30 \mathrm{kHz}, 70 \mathrm{~kW} / \mathrm{cm}^{2}\right)$ for $10-20$ seconds.

*Address correspondence to this author at the Application Technology Institute of China Petroleum Engineering Southwest Company, Qingyang Ditrict, Xiaoguanmiao, Street No. 25, Sichuan Chengdu City 610017, P.R. China; E-mail: dulei_writing@163.com

\subsection{Crystallization of Cefradine}

After adding the seed crystals to the reserved solution, the $\mathrm{pH}$ value of resulting solution was adjusted to 3.0-3.1 by adding dimethylamine/ethylenediamine $(1: 2, \mathrm{~V} / \mathrm{V})$. The solution was kept for $0.5 \mathrm{~h}$ under the higher temperature, and 1,2-propanediol at 0.2 ratio by volume was added to the mixture. The $\mathrm{pH}$ value of the mixture was then adjusted to $4.6-4.7$ by addition of dimethylamine/ethylenediamine $(1: 2$, $\mathrm{V} / \mathrm{V})$. The mixture was cooled and left standing for $0.5 \mathrm{~h}$. The crystals were washed twice with $95 \%$ ethanol and leached twice with absolute ethyl alcohol. After vacuum filtering, the crystals of cefradine were dried in a vacuum at $30^{\circ} \mathrm{C}$ for $1-2 \mathrm{~h}$.

\subsection{High-Performance Liquid Chromatography (HPLC)}

The HPLC system used was Agilent 1100 (Agilent, USA). The chromatographic system consisted of a polymeric reversed-phase PLRP-S HPLC column (1503 4.6 mm I.D., 5 $\mathrm{mm}$; Polymer Labs., Church Stretton, UK) with an in-line 2$\mathrm{mm}$ pre-filter. Analyses were performed at ambient temperature with a mobile phase of $10.5 \%(\mathrm{v} / \mathrm{v})$ acetonitrile in $20 \mathrm{mM}$ ammonium dihydrogen orthophosphate $(\mathrm{pH} 2.75)$ at a flow-rate of $1 \mathrm{~mL} / \mathrm{min}$. The UV detection wavelength used was $260 \mathrm{~nm}$ and sample aliquots of $100 \mathrm{~mL}$ were injected into the chromatographic system.

\subsection{Fourier Transforms Infrared Spectroscopy (FTIR)}

FTIR spectra were recorded with a Bruker Vector 33 spectrometer in the $500-4000 \mathrm{~cm}^{-1}$ range at a resolution of 2 $\mathrm{cm}^{-1} ; 32$ scans were run. Samples were diluted at $1 \%$ concentration with $\mathrm{KBr}$ mixing powder and pressed to obtain self-supporting disks.

\subsection{X-Ray Diffraction Studies (XRD)}

X-ray diffraction analysis was performed using the D/max-IIIA (SHIMADZU Inc., Japan) to detect the physical characteristics and crystallinity of the cefradine. The measuring unit consisted of a rotating anode in transmission technique with the following specifications: $\mathrm{Cu} \quad \mathrm{K} \alpha_{1}$ radiation generated at $30 \mathrm{~mA}$ and $40 \mathrm{kV}$. The scanning speed was $10 \% \mathrm{~min}$, from $5 \circ$ to $55^{\circ}$, with a step size of $0.02 \circ$. 


\section{RESULTS AND DISCUSSIONS}

\subsection{The Effect of Dissolving Temperature on Cefradine Crystallization}

The process of dissolving cefradine is the reaction of cefradine with $\mathrm{HCl}$, which is obviously influenced by different temperatures (Fig. 1). Both the crystal yield and the purity of cefradine decrease rapidly with increasing dissolving temperature above $15^{\circ} \mathrm{C}$. However, the content of cefalexin in solution increases rapidly as temperature rises above $15^{\circ} \mathrm{C}$ (Fig. 2). The results show that cefalexin is the main product of the side reaction [16].

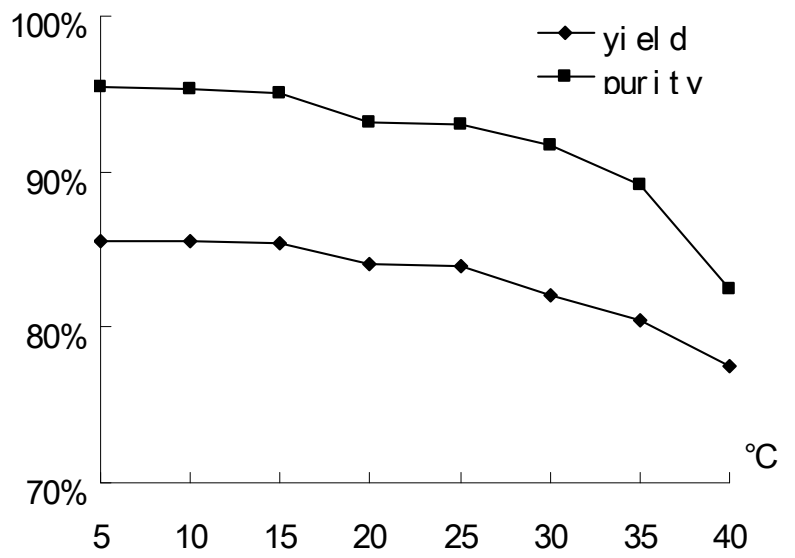

Fig. (1). The effect of dissolving temperature on cefradine crystallization.

\subsection{Initial and Cooling Temperature for Crystallization}

In the crystallization step, the initial and final temperatures were regulated to optimize the crystallizing process. Raising the initial temperature results in a noticeable increase in average crystal size (Fig. 3). Conversely, crystal purity declines greatly as the temperature rises. These results show that a higher initial temperature accelerates not only the speed of crystallization of cefradine, but also that of the side reaction in the system. In addition, the growth rate of crystal size is lower when the solution temperature is above $30^{\circ} \mathrm{C}$ because the generation of new seed crystals offsets the increased reaction speed.

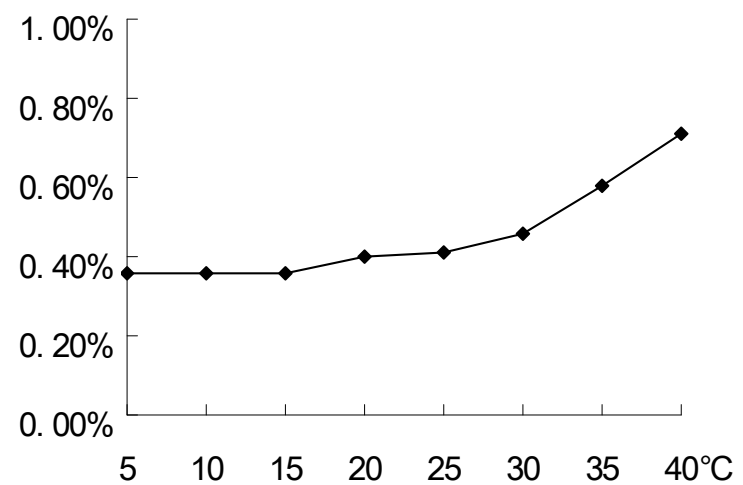

Fig. (2). The content of cefalexin at different dissolving temperatures.

In the crystallization process, a cooling strategy is often used to reduce the solubility of a molecule and to improve the crystal yield. Moreover, the lower temperature can suppress the oxidation reaction of cefradine in solution. A slight increase in crystal yield, and in crystal purity as well, was observed as the cooling temperature of cefradine crystallization was lowered (Fig. 4).

\subsection{Optimize Agent of Crystal Feature}

It is often useful to add specific agents to optimize the process of crystallization. The agents are used to increase the solubility of the molecule or to slow the speed of crystallization by changing thermodynamic and dynamic parameters in the crystalline system. In this study,

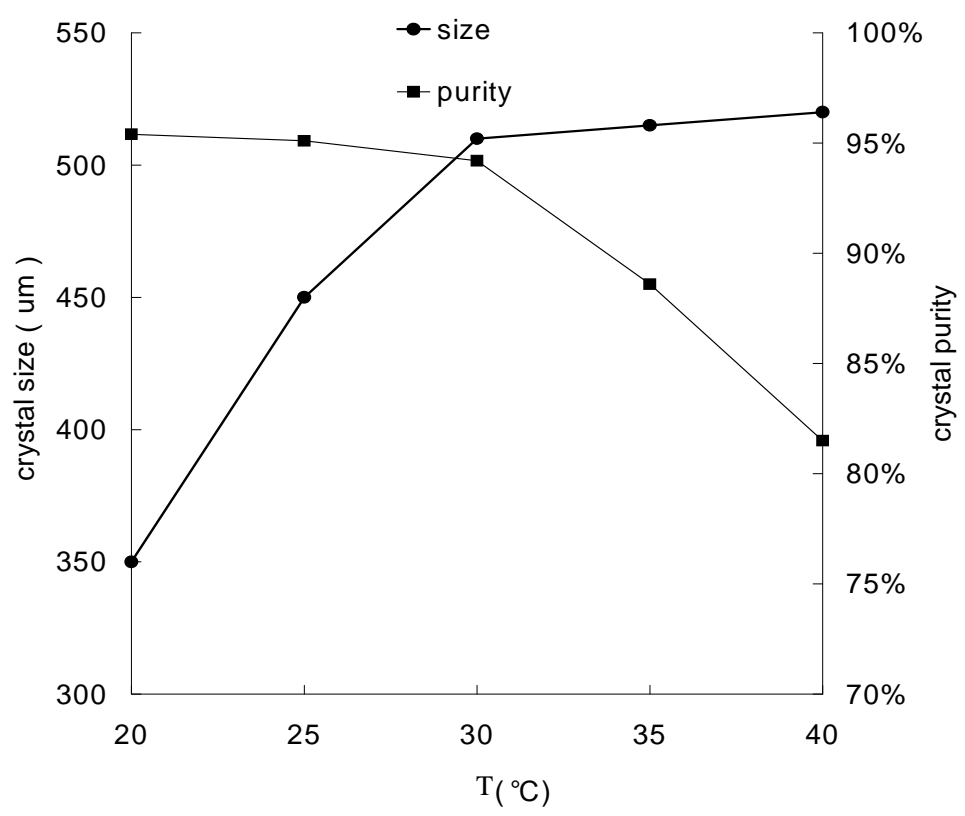

Fig. (3). The effect of initial crystal temperature on cefradine crystallization. 
Conventional organic solvents with arginine was compared, which is often mixed with cefradine in commodity products. It is found that 1,2-propanediol displays the best performance and can be used as an adjuvant in cefradine crystallization (Table 1).

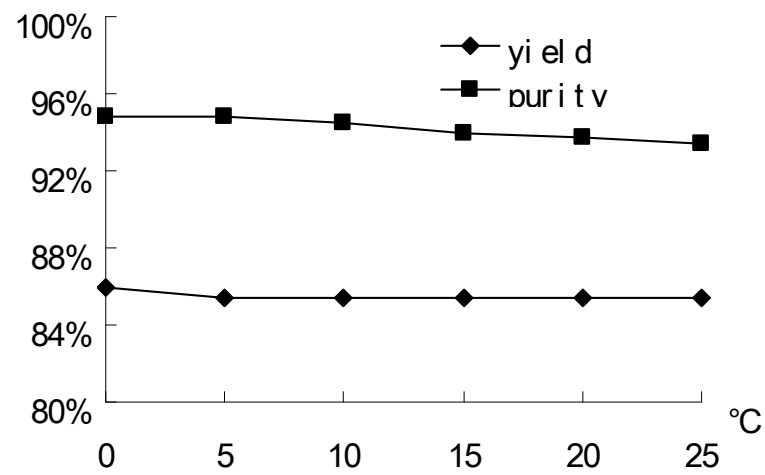

Fig. (4). The effect of cooling temperature on cefradine crystallization.

Table 1. Comparison of the Agents for Optimizing Cefradine Crystal Structure

\begin{tabular}{|c|c|c|c|c|c|}
\hline & $\begin{array}{c}\text { Crystal } \\
\text { Structure }\end{array}$ & $\begin{array}{c}\text { Average } \\
\text { Size } \\
(\boldsymbol{\mu} \mathbf{m})\end{array}$ & $\begin{array}{c}\text { Yield } \\
\mathbf{( \% )}\end{array}$ & $\begin{array}{c}\text { Purity } \\
\mathbf{( \% )}\end{array}$ & $\begin{array}{c}\text { Content of } \\
\text { Cefalexin } \\
(\mathbf{\%})\end{array}$ \\
\hline \hline alcohol & rhabditiform & 350 & 85.0 & 95.2 & 0.39 \\
\hline acetonitrile & aciculiform & 300 & 84.6 & 95.3 & 0.38 \\
\hline isopropanol & slender & 330 & 84.5 & 96.1 & 0.38 \\
\hline propyl alcohol & slender & 350 & 84.6 & 94.8 & 0.39 \\
\hline butanol & slender & 350 & 84.6 & 94.8 & 0.39 \\
\hline methanol & flake & 300 & 83.5 & 91.6 & 0.42 \\
\hline aether & aciculiform & 280 & 84.2 & 94.5 & 0.42 \\
\hline acetone & aciculiform & 260 & 84.7 & 95.1 & 0.38 \\
\hline 1,2-propanediol & clavate & 380 & 84.9 & 96.4 & 0.38 \\
\hline arginine & aciculiform & 300 & 84.2 & 94.0 & 0.38 \\
\hline
\end{tabular}

\subsection{Optimization of Cefradine Crystallization}

According to the previous results, the optimal conditions for cefradine crystallization are: dissolving temperature, $15^{\circ} \mathrm{C}$; initial temperature, $30^{\circ} \mathrm{C}$; cooling temperature, $0^{\circ} \mathrm{C}$; and addition of a 0.2 ratio by volume of 1,2-propanediol as the adjuvant reagent (Table 2). Compared with the control, the crystal yield increased from $89.4 \%$ to $92.3 \%$. The crystal purity also increased from $90.7 \%$ to $98.2 \%$. The average size of a cefradine crystal increased from $220 \mu \mathrm{m}$ to $500 \mu \mathrm{m}$ (Fig. 5). The content of cefalexin in the crystals decreased from $2.1 \%$ to $0.36 \%$.

Through a comparison of the characteristics of a cefradine crystal using FTIR and XRD, it can be concluded that there is no apparent difference in either the composition or the crystal structure between the cefradine crystals
Table 2. The Result of Cefradine Crystallizing in Optimizing Condition

\begin{tabular}{|c|c|c|}
\hline & Control & Optimizing Condition \\
\hline \hline Crystal yield $(\%)$ & 89.4 & 92.3 \\
\hline Crystal purity $(\%)$ & 90.7 & 98.2 \\
\hline Average size of crystal $(\mu \mathrm{m})$ & 220 & 500 \\
\hline Content of cefalexin $(\%, \mathrm{w} / \mathrm{w})$ & 2.1 & 0.36 \\
\hline Water content $(\%, \mathrm{w} / \mathrm{w})$ & 3.9 & 3.7 \\
\hline
\end{tabular}
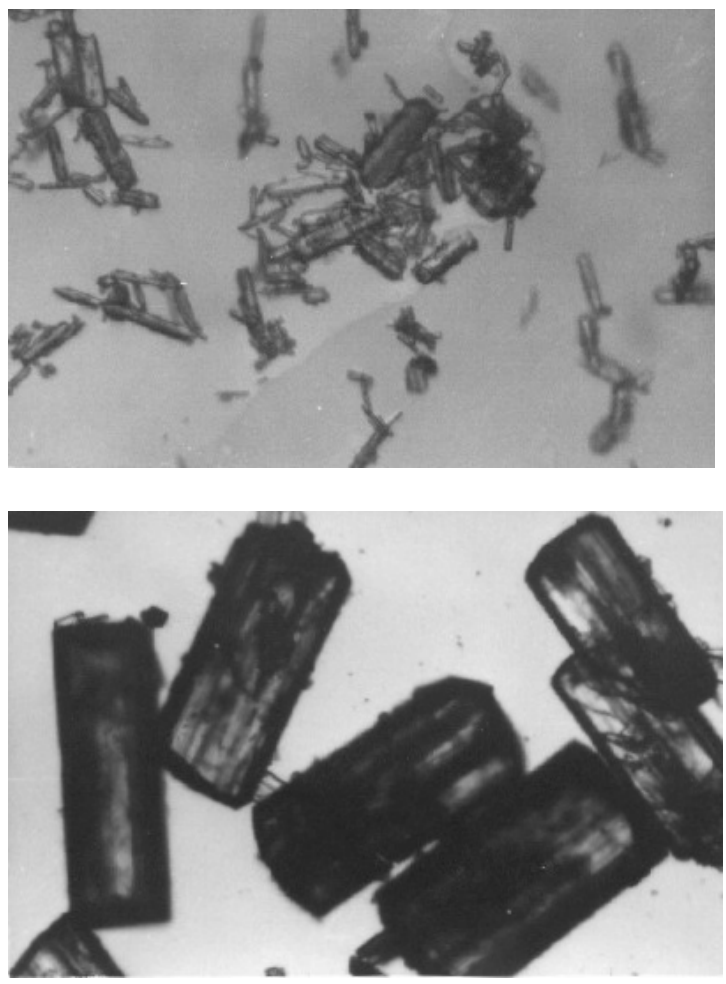

Fig. (5). Crystal photo of cefradine crystal (top: commercial crude powers, bottom: optimizing crystal. $100 \times)$.

obtained from the optimized condition in our experiments with the standard commercially available cefradine crystal (Figs. 6-8) we used as a starting material.
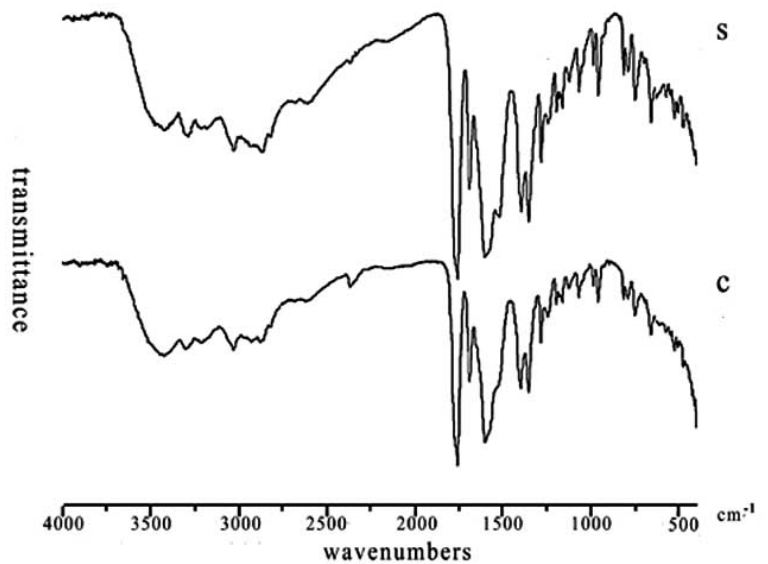

Fig. (6). FTIR spectra of cefradine under optimized crystallization conditions (s) vs Standard (c). 


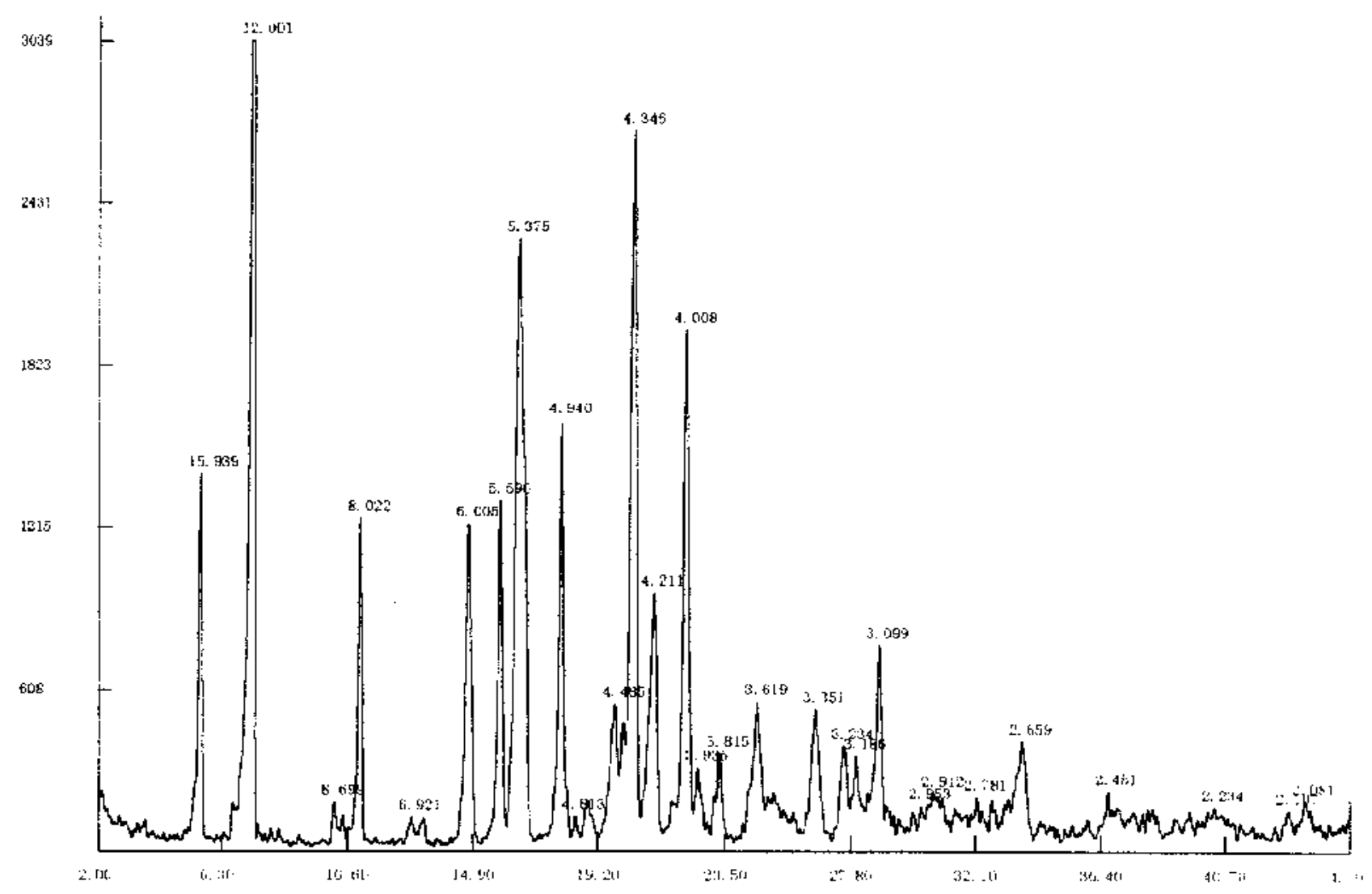

Fig. (7). X-rays diffraction of a cefradine crystal produced under optimized conditions.

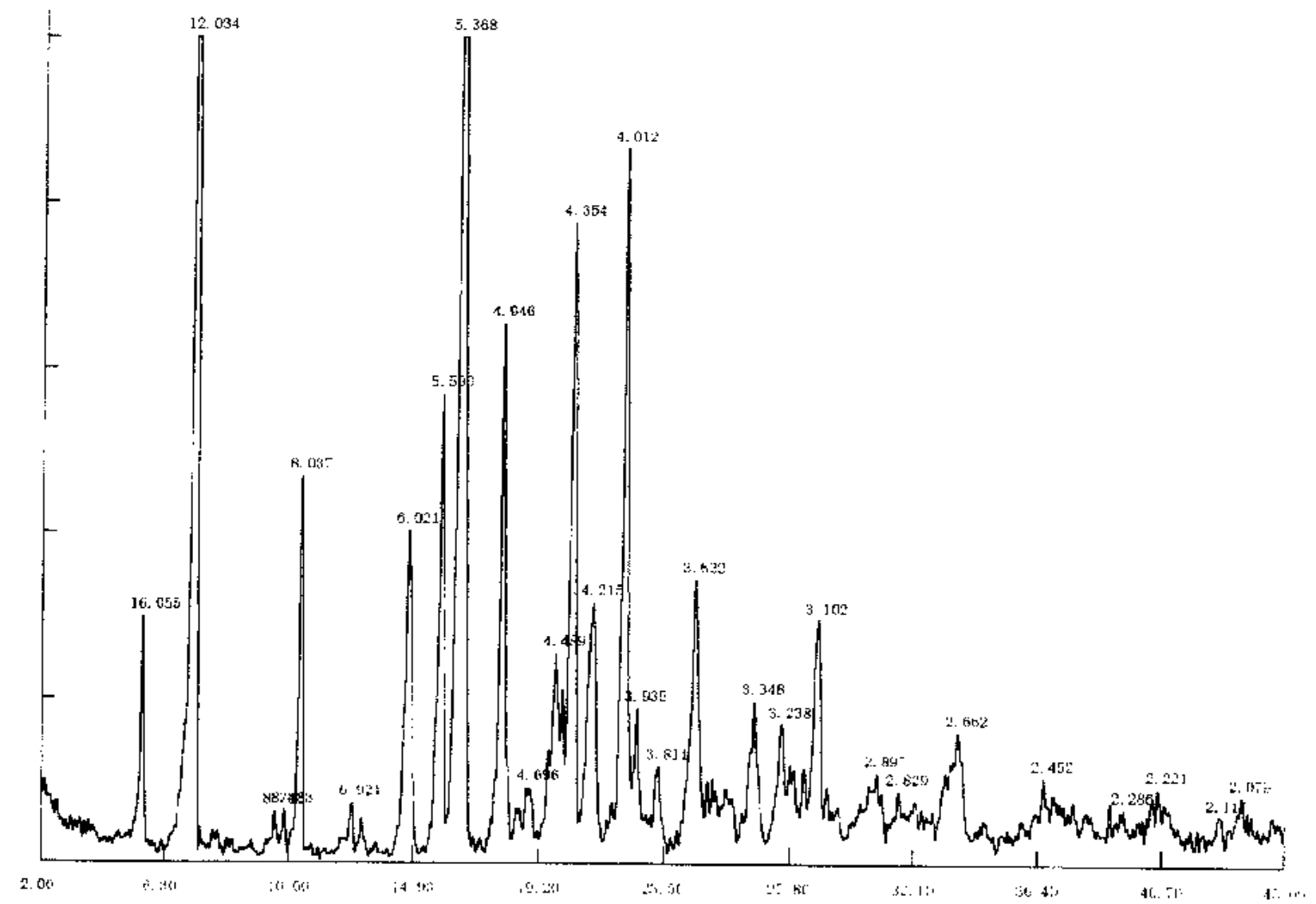

Fig. (8). X-ray diffraction pattern of a standard cefradine crystal. 


\section{CONCLUSIONS}

In this paper, we discuss different conditions for cefradine crystallization, including dissolving temperature, initial and cooling temperature for crystallization, and adjuvant agents for optimizing crystal characteristics. The optimal conditions for cefradine crystallization are: dissolving temperature, $15^{\circ} \mathrm{C}$; initial temperature for crystallization, $30^{\circ} \mathrm{C}$; cooling temperature during crystallization, $0^{\circ} \mathrm{C}$; and addition of 1,2-propanediol at a 0.2 ratio by volume as the adjuvant agent for crystal characteristics. The yield of cefradine crystals is about $92 \%$ under these conditions, and the purity of the obtained cefradine crystals is over $98 \%$. The average size of a cefradine crystal approaches $500 \mu \mathrm{m}$, and the content of cefalexin in the crystals is reduced to only $0.36 \%$.

\section{REFERENCES}

[1] Joseph, E.D.; Harold, E.A. A new class of semisynthetic penicillins and cephalosporins derived from D-2-(1,4-cyclohexa- dienyl) glycine. J. Med. Chem., 1971, 14(2), 117-119.

[2] Jie, Z.; Shen, Z.; Yang, Y.; Chen, J.F. Preparation and characterization of uniform nanosized cephradine by combination of reactive precipitation and liquid anti-solvent precipitation under high gravity environment. Int. J. Pharm., 2005, 301, 286-293.

[3] Frank, L.W.; Joseph, E.D.; Georges, G..B.; Jack, B. Alpha-aminocyclohexadienylalkylene- -penicillins and cephalosporins. U.S. Pat., US3485819, 1969.
[4] Herman, B.B.; Treuner, U. 2-(Thiocarbonylamino)acetamidocephalosporanic acid compounds. U.S. Pat., US3862941, 1975.

[5] Diassi, P.A.; Atwal, M.S. Process for the preparation of 7-(D-2amino-2(1,4-cyclo-hexadienyl) acetamido) desacetoxycephalosporanic acid and 7-(D-2-amino-2-(1,4-cyclohexadienyl) acetamido) cephalosporanic acid. U.S. Pat., 3912726, 1975.

[6] Robinson, C.A. Intermediates for preparing cephalosporins and methods of production. U.S. Pat., US3965098, 1976.

[7] Faarup, P. Method of preparing a sparingly soluble complex of cephalexin. U.S. Pat., US4003896, 1977.

[8] Broggi, R.; Falciani, M. Process for preparing cephalosporines. U.S. Pat., US4139702, 1979.

[9] Bouzard, D.; Weber, A.; Stemer, J. Process for the preparation of the crystalline monohydrate of 7-[D- $\alpha$-a $\alpha$-(p-hydroxyphenyl)acetamido]-3-methyl-3-cephem-4-ca rboxylic acid. U.S. Pat., US4160 863, 1979.

[10] Walker, D.; Silvestri, H.H.; Sapino C.; Johnson, D.A. Production of cephalosporins. U.S. Pat., US4223135, 1980.

[11] Palomo-coll, A.; Palomo-coll, A.L. Process for the preparation of solutions of 7-aminocephalosporanic acids. U.S. Pat., US4405782, 1983.

[12] Meseguer, J.D.; Codes, R.B.; Ciriza, S.A. Stable cephradine hydrate. U.S. Pat., US5278157, 1994.

[13] Diago, J.; Ludescher, J. Beta lactam production. U.S. Pat., US5719276, 1998

[14] Diago, J.; Ludescher, J. Processes for the production of 6- $\alpha$ aminoacyl-penicillin and 7-alpha. U.S. Pat., US5840885, 1998.

[15] Centellas, V.; Diago, J.; Ludescher, J. Silylation process. U.S Patent, US5998610, 1999

[16] Christel, H.; Eugène, R.; Valère, B.; Josiane, T.; Martine, P.; Roger, B.; Gerard, J.; Jos, H. Synthesis of potential impurities of cefalexin and cefradine. Archiv. Pharm., 1994, 327(4), 215-219. 